\title{
Prevalence of Depression and Associated Factors among HIV Patients Seeking Treatments in ART Clinics at Harar Town, Eastern Ethiopia
}

Mahir Mohammed ${ }^{1}$, Bezatu Mengistie ${ }^{2}$, Yadeta Dessie ${ }^{2}$ and Wanzahun Godana ${ }^{3 *}$

${ }^{1}$ Harari Regional Health Bureau, Harar, Ethiopia

${ }^{2}$ College of Medicine and Health Sciences, School of Public Health, Haramaya University, Harar, Ethiopia

${ }^{3}$ College of Medicine and Health Sciences, School of Public Health, Arba Minch University, Arba Minch, Ethiopia

\begin{abstract}
Background: Depression HIVIAIDS and are projected to be the world's two leading causes of disability by 2030 . Depression among people with HIVIAIDS is very high also affects 121 million people globally. The study was aimed at estimating prevalence of depression and associated factors among adult patients seeking ART treatment in Harar, East Ethiopia
\end{abstract}

Method: An institutional based cross-sectional study was carried out in March 2013. A total of 740 study subjects were included in the study. Proportionate stratified random sampling technique was used to select participants. Data was collected using pre-tested structured questionnaire by trained data collectors. Bivariate and multivariate logistic regression analyses were undertaken to identify predictors of depression. The association between explanatory and dependent variable was reported using odd ratio and its $95 \%$ confidence interval.

Results: prevalence of depression among HIV patients was $45.8 \%$. In multivariate models, independently associated with sex being male (AOR 1.633; $95 \% \mathrm{Cl} 1.138,2.342)$ and Marital status being widowed $(3.128 ; 95 \%$ $\mathrm{Cl} 1.700,5.757)$ and Monthly income earning 500-1000 (1.924; 95\% 1.159, 3.195) the last scheduled clinic visit in a month (AOR 22.729; 95\% 2.450, 210.873) and last time missed any of medication $(5.274 ; 95 \% \mathrm{Cl} 2.583,10.768)$ and Teased, insulted or sworn at (AOR 2.286; 95\% Cl 1.216,4.297) Gossiped about (AOR 2.990; 95\% Cl 1.682,5.313) had significant association.

Conclusion: From findings of this study, it emerged that depression is high among people living with HIV who participated in the study. Being male and lack of social support were statistically associated with depression. On the other hand, depressive morbidity is hence challenges to uptake of medical recommendations among PLWHA accessing care and treatment services, with potential implications for HIV treatment outcomes.

Keywords: Depression; HIV/AIDS; Adults; Ethiopia

\section{Introduction}

More than 33 million people are living with HIV throughout the world. The greatest burden of the disease is concentrated in developing countries. Mental health is highly intertwined with communicable diseases such as HIV [1]. In Ethiopia on 2009 the adult prevalence rate is estimated to be $2.1 \%$, there are a total of 980,000 people living with HIV/AIDS and an estimated number of death due to AIDS is 67,000. The age group 15-24 had the highest prevalence of 5\%. The adult HIV prevalence for Harari Region was estimated to be $3.5 \%$ for the year 2009 [2]. Not only do mental disorders such as schizophrenia and depression put people at a higher risk for contracting HIV, living with HIV and its accompanying stigmatization can lead to poor mental health outcomes [3].

Depression is one of the most common mental health disorders people with HIV experience on year 2007 [3]. Depression is among the most frequently observed psychiatric disorder among HIV/AIDS patients. The overall prevalence is difficult to identify across the globe as a result of the wide variations of the problem. It is estimated to range from 20 to above $70 \%$ and also has been associated with increased risky behaviors, noncompliance to treatment, higher risk for co-morbid disorders and decreased survival. Therefore, failure to recognize and treat depression endangers the patient as well as the community at large [4-6].

There are evidences that prevalence of mental illnesses in HIVinfected individuals is substantially higher than in the general population. In addition, HIV tends to be concentrated in highly vulnerable, marginalized and stigmatized populations; especially, sex workers, homosexuals, drug users and prisoners have higher levels of mental health disorders than the general population. Increased psychological distress among people with HIV infection is common. Many studies in both low- and high income countries have reported higher rates of depression in HIV-positive people compared with HIV negative control groups. The level of distress often seems to be related to the severity of symptoms of HIV infection [4-6]. Mental disorders, including substance use disorders, are risk factors for contracting HIV, and the presence of HIV/AIDS increases the risk of development of mental disorders. The resulting comorbidity complicates help-seeking, diagnosis, quality of care provided, treatment and its outcomes, and adherence. This is why the diagnosis of mental health problems in HIV-infected individuals faces several barriers. The other reason why diagnosis of mental health problem come from Patients perception often do not reveal their psychological state to health-care professionals

*Corresponding author: Wanzahun Godana, College of Medicine and Health Sciences, School of Public Health, Arba Minch University, Arba Minch, Ethiopia Tel: 251913689198; E-mail: wanzanati2011@gmail.com

Received January 08, 2015; Accepted June 09, 2015; Published June 19, 2015

Citation: Mohammed M, Mengistie B, Dessie Y, Godana W (2015) Prevalence of Depression and Associated Factors among HIV Patients Seeking Treatments in ART Clinics at Harar Town, Eastern Ethiopia. J AIDS Clin Res 6: 474. doi:10.4172/2155-6113.1000474

Copyright: (c) 2015 Mohammed M, et al. This is an open-access article distributed under the terms of the Creative Commons Attribution License, which permits unrestricted use, distribution, and reproduction in any medium, provided the original author and source are credited. 
for fear of being stigmatized further. Also, health-care professionals are often not skilled in detecting psychological symptoms and, even when they do, they often fail to take the necessary action for further assessment, management and referral $[7,8]$.

One meta-analysis looking at the relationship between HIV infection and risk of depressive disorders found that living with HIV posed a greater risk of having major depressive disorder [7]. Furthermore, co-morbidity of mental illness and HIV lead to poor healthcare seeking patterns, diagnosis, and treatment [1]. In a study investigating the effect of psychological factors on antiretroviral (ART) uptake, depression was highly associated with poor ART adherence [9]. The interrelatedness of mental health and HIV make it important to consider adherence interventions that address both issues simultaneously. Especially in developing countries where mental health facilities are underdeveloped, HIV is an epidemic, and factors such as poverty exacerbate mental health problems.

Mental health problems related with HIV/AIDS can result from the psychological impact of having a fatal disease; stem from the effects of psychosocial stressors associated with the illness like stigma and discrimination. It may result from actual neurological changes in the physical and chemical structures of the central nervous system that occur because of the HIV virus, opportunistic infections, and also due to treatments. Majority of HIV positive psychiatric patients actually suffer from many different disorders. Like other chronic patients, HIV/AIDS infected individuals face a number of the same stressors such as long-term discomfort, physical deterioration, physical and economic dependence and eventual death. HIV/AIDS may also lead to mood disorders [5]. The prevalence of anxiety and depressive disorders is high among HIV/AIDS patients [10,11]. The present study was aimed to estimating prevalence of depression and associated factors among adult patients seeking ART treatment in Harar Town, East Ethiopia.

\section{Materials and Methods}

\section{Study population and setting}

Facility based cross-sectional study was conducted from March 1 to 31, 2013 in Harari Regional State, which is located in the eastern part of Ethiopia. According to the Ethiopian Central Statistics Authority's 2007 report, the Harari Region has a total population of 183,344, of whom 92,258 were men and 91,086 women, and is situated at $526 \mathrm{kms}$ from Addis Ababa. The first Hospital was built in 1903 to serve about 25,000 people but now it is serving more than 5 million people. A total of 7,122 adult HIV/AIDS patients have been enrolled to HIV/AIDS care and support programs, of which 4,056 patients were in pre-ART care, and 2,790 were on ART care.

The source populations were HIV/AIDS patients who were enrolled to ART care clinic in public health facilities and the study populations were people aged 18 years and older who were actively taking ARV drugs, and/or those who followed HIV/AIDS chronic care but not yet started ART.

The required sample size was determined using two population proportion formula, where $\mathrm{n}$ is the sample size, $\mathrm{z}$ is the standard normal score set at $1.96, \mathrm{~d}$ is the desired degree of accuracy and $\mathrm{p}$ is the estimated prevalence of the target population. By taking $\mathrm{p} 1=42.1 \%$ $(\mathrm{P}=1$ prevalence of stigma in patients started ART $)$ and $\mathrm{P} 1=31.9 \%$ $(\mathrm{P} 2=$ prevalence of stigma in patients pre $-\mathrm{ART}$ treatment $) \mathrm{P} 1 \& \mathrm{P} 2=$ prevalence of perceived stigma among HIV patients according to study conducted in Jimma University Hospital $[10,12]$. $\mathrm{z}=1.96$ the computed sample size included $10 \%$ non-response rate, the total sample size computed was $\mathbf{7 6 3}$.

From the total of seven public health facilities, three public hospitals and 4 health centers which provide ART service were selected. From selected health facilities the number of patients served at each clinic per day was determined on the basis of client/patient flow and then the total number of client/Patients during the whole study period calculated by summing up at each ART clinic and the calculated sample size was distributed proportionally stratified by the seven public health institutions. Then systematic random sampling was used to select the study subjects. From seven health facilities average patient loads per day were 80 , so the total number of client load in one month is 1760 . Using these two parameters the sampling interval every third clients were selected as the study unit. Finally adding the sampling interval to the preceding number the next client was selected consecutively till sample size is completed. Whenever the sampled client did not fulfill the inclusion criteria, immediately the next client who fulfilled the criteria were interviewed.

Those who were actively following HIV/AIDS chronic care in 7 ART clinics and aged 18years and older were included in the study while patients who were not able to communicate or critically ill and Patients taking ARV prophylaxis for the sole purposes of prevention of mother-to-child transmission were excluded. Prior to data collection, ethical approval was obtained from ethical review committee of Haramaya University, College of Medicine and Health Sciences. For all participants informed consent was obtained.

\section{Data collection tool and procedures}

Depression: It is having a depressed mood on a daily basis for a minimum duration of two weeks. It can be also manifested in the form of loss of interest or pleasure in nearly all activities including enjoyable activities [13].

\begin{tabular}{|c|c|}
\hline Minimal depression & PHQ score of 1-4 \\
\hline Mild depression & PHQ score of 5-9 \\
\hline Moderate depression & PHQ score 10-14 \\
\hline Moderately severe depression & PHQ score 15-19 \\
\hline Severe depression & PHQ score 20-27 [14] \\
\hline
\end{tabular}

Adherence: The extent to which a person's behaviour in taking medications, following a diet and/or executing lifestyle changes, corresponds with agreed recommendations from a healthcare provider (WHO 2003:3). In this study, adherence refers to compliance of the patient's behaviour in taking ARV medication.

The data was collected from March $1^{\text {st }}$ to March 312013 using structured interviewer administered questionnaire. Three data collectors (two ART adherence counselors, and one HIV/AIDS specialist nurse) and one supervisor were recruited. Two days training was given. The data collection process was followed daily by the supervisor and principal investigators

\section{Statistical analysis}

Questionnaires were checked for completeness, coded, and entered into SPSS version 16 statistical package. Descriptive analysis was used to describe the socio-demographic characteristics of the study participants. Logistic regressions analysis was computed to assess the associations of the various factors against the level of depression. Variables with a p-value of less than 0.25 in the bivariate analysis were entered into the final model. P-value $\leq 0.05$ at $95 \%$ CI was considered 
Citation: Mohammed M, Mengistie B, Dessie Y, Godana W (2015) Prevalence of Depression and Associated Factors among HIV Patients Seeking Treatments in ART Clinics at Harar Town, Eastern Ethiopia. J AIDS Clin Res 6: 474. doi:10.4172/2155-6113.1000474

Page 3 of 6

for strength of statistically significant association between predictors and outcome variable.

\section{Result}

\section{Socio-demographic characteristics of respondents}

A total of 740 study participants interviewed, giving a response rate of $97 \%$. About $468(63.2 \%)$ were female and majority of the clients were in the age category of 30-39 years old followed by age category of greater than 40 years old were $211(28.5 \%)$ respectively.

More than half of the client's 483 (65.3\%) were Orthodox by religion and most of the respondents were married $341(46.1 \%)$ and regarding education level of the respondents $298(40.3 \%)$ were attended 1-8grade, and majority were Amhara 439 (59.3\%) in their ethnicity (Table 1).

\begin{tabular}{|c|c|c|c|}
\hline Characteristics & & Frequency & $\%$ \\
\hline \multicolumn{4}{|l|}{ Sex } \\
\hline & Male & 272 & 36.8 \\
\hline & Female & 468 & 63.2 \\
\hline \multicolumn{4}{|l|}{ Age } \\
\hline & $<20$ & 6 & 0.8 \\
\hline & $20-29$ & 173 & 23.4 \\
\hline & $30-39$ & 350 & 47.3 \\
\hline & $>=40$ & 211 & 28.5 \\
\hline \multirow[t]{2}{*}{ Residence } & Urban & 690 & 93.2 \\
\hline & Rural & 50 & 6.8 \\
\hline \multirow[t]{3}{*}{ Religion } & Muslim & 188 & 25.4 \\
\hline & Orthodox & 483 & 65.3 \\
\hline & Protestant /Others & 69 & 9.3 \\
\hline \multirow[t]{5}{*}{ Education level } & Can't read and write & 60 & 8.1 \\
\hline & Read \&Write only & 162 & 21.9 \\
\hline & 1-8 grade & 298 & 40.3 \\
\hline & $9-12$ grade & 73 & 9.9 \\
\hline & Above 12 grade & 147 & 19.9 \\
\hline \multirow[t]{5}{*}{ Ethnicity } & Oromo & 208 & 28.1 \\
\hline & Amhara & 439 & 59.3 \\
\hline & Harari & 13 & 1.8 \\
\hline & Gurage & 43 & 5.8 \\
\hline & Others & 37 & 5.0 \\
\hline \multirow[t]{5}{*}{ Marital status } & Unmarried & 66 & 8.9 \\
\hline & Married & 341 & 46.1 \\
\hline & Divorced & 194 & 26.2 \\
\hline & Widow & 131 & 17.7 \\
\hline & Separated/cohabiting & 8 & 1.1 \\
\hline \multirow[t]{7}{*}{ Occupation } & Unemployed & 157 & 21.2 \\
\hline & Gov't employee & 106 & 14.3 \\
\hline & Merchant & 125 & 16.9 \\
\hline & Farmer & 26 & 3.5 \\
\hline & Self employed & 199 & 26.9 \\
\hline & Day laborer & 58 & 7.8 \\
\hline & Others & 69 & 9.3 \\
\hline \multirow[t]{4}{*}{ Monthly Income } & $<500$ Eth birr & 320 & 43.2 \\
\hline & 500-1000 Eth birr & 207 & 28.0 \\
\hline & $1000-1500$ Eth birr & 80 & 10.8 \\
\hline & $>1500$ Eth birr & 133 & 18.0 \\
\hline
\end{tabular}

Table 1. Demographic and Socio Economic characteristics of people living with HIV on ART program, in Harari Region, Ethiopia, March 2013.

\begin{tabular}{|c|c|c|c|}
\hline Characteristics & Options & Frequency & $\%$ \\
\hline \multirow{2}{*}{ Little interest or pleasure in doing things } & Yes & 426 & 57.6 \\
\hline & No & 314 & 42.4 \\
\hline \multirow{2}{*}{ Feeling down, depressed, or hopeless } & Yes & 481 & 65.0 \\
\hline & No & 259 & 35.0 \\
\hline \multirow{2}{*}{ staying asleep, or sleeping too much } & Yes & 471 & 63.6 \\
\hline & No & 269 & 36.4 \\
\hline \multirow{2}{*}{ Feeling tired or having little energy } & Yes & 537 & 72.6 \\
\hline & No & 203 & 27.4 \\
\hline \multirow[t]{2}{*}{ Poor appetite or overeating } & Yes & 470 & 63.5 \\
\hline & No & 270 & 36.5 \\
\hline \multirow{2}{*}{$\begin{array}{l}\text { Feeling bad about yourself, or that you } \\
\text { are a failure or have let yourself or your family } \\
\text { down }\end{array}$} & Yes & 382 & 51.6 \\
\hline & No & 358 & 48.4 \\
\hline \multirow{2}{*}{$\begin{array}{l}\text { Trouble concentrating on things, such as } \\
\text { reading the newspaper or watching TV }\end{array}$} & Yes & 402 & 54.3 \\
\hline & No & 338 & 45.7 \\
\hline \multirow{2}{*}{$\begin{array}{l}\text { Moving or speaking so slowly that other } \\
\text { people could have noticed. }\end{array}$} & Yes & 395 & 53.4 \\
\hline & No & 345 & 46.6 \\
\hline \multirow{2}{*}{$\begin{array}{l}\text { Thoughts that you would be better off dead, or } \\
\text { of hurting yourself in some way. }\end{array}$} & Yes & 353 & 47.7 \\
\hline & No & 387 & 52.3 \\
\hline \multirow{2}{*}{$\begin{array}{l}\text { Trouble concentrating on things, such as } \\
\text { reading the newspaper or watching TV }\end{array}$} & Yes & 402 & 54.3 \\
\hline & No & 338 & 45.7 \\
\hline \multirow{2}{*}{$\begin{array}{l}\text { Moving or speaking so slowly that other } \\
\text { people could have noticed. }\end{array}$} & Yes & 395 & 53.4 \\
\hline & No & 345 & 46.6 \\
\hline \multirow{2}{*}{$\begin{array}{l}\text { Thoughts that you would be better off dead, or } \\
\text { of hurting yourself in some way. }\end{array}$} & Yes & 353 & 47.7 \\
\hline & No & 387 & 52.3 \\
\hline
\end{tabular}

Table 2. Factors assessing depression in $\mathrm{PHQ}$ scale among people living with HIV on ART program in Harari Region, Ethiopia, March 2013.
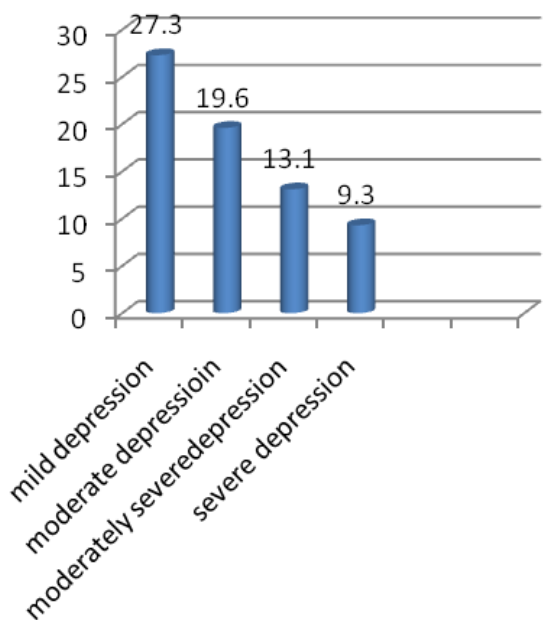

Figure 1: Depression score of people living with HIV on ART Clinics, in Harari Region, Ethiopia, March 2013.

Frequency of clinical symptoms in PHQ scale among people living HIV

The most common depressive symptoms that were presented by depressed respondents were little interest or pleasure in doing things 426 (57.6\%), feeling down, depressed or hopeless 481(65.0\%); staying a sleep, or sleeping too much $471(63.6 \%)$, feeling tired or having little energy 537 (72.6\%), poor appetite or over eating 470(63.5\%) (Table 2).

Depression scoring among the study participants revealed the following results, $27.3 \%$ experienced mild depression, $19.6 \%$ moderate and $9.3 \%$ experienced severe depression (Figure 1). 


\section{Bivariate analysis of association between socio-demographic characteristics and depression}

Bivariate analysis of was done to identify variables that associated with depression in the study. Being Males were found to be $44 \%$ more likely to be depressed compared to females (COR=1.445, 95\% CI $1.068,1.956)$. Another variable that found associated with depression were marital status of the clients, being widowed individuals were 2.6 times more likely to develop depression than Single (COR=2.676, 95\% CI $1.510,4.745)$ and being Self-employed were 3 times more likely depressed compared to being Unemployed (COR=3.185, 95\% CI 1.306, 7.765). Respondents who earned less than 500 Eth.birr per month were found to be 1.4 times more likely to develop depression than to those who earned more than $>1500$ Eth.birr. (COR=1.437, 95\% CI 0.956, 2.160) (Table 3).

\section{Factors associated with depression among people living with HIV}

An adjusted multivariable model was created by forward stepwise logistic regression using the factors that were significant with the bivariate model, clients who are males were found to be 1.6 times more risk of developing depression than females ( $\mathrm{AOR}=1.633,95 \% \mathrm{CI} ; 1.138,2.342)$.

\begin{tabular}{|c|c|c|c|}
\hline \multirow[t]{2}{*}{ Characteristics } & \multicolumn{2}{|c|}{ Depression } & \multirow[t]{2}{*}{ COR $(95 \% \mathrm{Cl})$} \\
\hline & YES (\%) & NO (\%) & \\
\hline \multicolumn{4}{|l|}{ Sex } \\
\hline Male & $109(40.1)$ & $163(59.9)$ & $1.445(1.068,1.956)^{*}$ \\
\hline Female & $230(49.1)$ & $238(50.9)$ & 1 \\
\hline \multicolumn{4}{|l|}{ Age } \\
\hline$<20$ years & $3(50.0)$ & $3(50.0)$ & 1 \\
\hline $21-30$ years & $82(47.4)$ & $91(52.6)$ & $1.110(0.218,5.652)$ \\
\hline $31-39$ & $164(46.9)$ & $186(53.1)$ & $1.134(0.226,5.697)$ \\
\hline$>=40$ & $90(42.7)$ & $121(57.3)$ & $1.344(0.265,6.817)$ \\
\hline \multicolumn{4}{|l|}{ Education level } \\
\hline Can't read and write & $21(6.2)$ & $39(9.7)$ & 1 \\
\hline Read \&Write only & $68(20.1)$ & $94(23.4)$ & $0.774(0.402,1.377)$ \\
\hline 1-8 grade & $142(42.2)$ & $155(38.7)$ & $0.584(0.328,1.039)$ \\
\hline $9-12$ grade & $38(11.2)$ & $35(8.7)$ & $0.496(0.246,1.000)$ \\
\hline Above 12 grade & $69(20.4)$ & $78(19.5)$ & $0.609(0.327,1.133)$ \\
\hline \multicolumn{4}{|l|}{ Marital status } \\
\hline Single & $39(59.1)$ & $27(40.9)$ & 1 \\
\hline Married & $167(49.0)$ & $174(51.0)$ & $1.505(0.882,2.569)$ \\
\hline Widowed & $68(35.1)$ & $126(64.9)$ & $2.676(1.510,4.745)^{*}$ \\
\hline $\begin{array}{l}\text { Divorced/separated } \\
\text { /cohabiting }\end{array}$ & $65(46.8)$ & $74(53.2)$ & $1.644(0.909,2.976)$ \\
\hline \multicolumn{4}{|l|}{ Occupation } \\
\hline Unemployed & $92(58.6)$ & $65(41.4)$ & 1 \\
\hline Gov't employee & $58(54.7)$ & $48(45.3)$ & $1.171(0.713,1.926)$ \\
\hline Merchant & $55(44.0)$ & $70(56.0)$ & $1.801(1.120,2.897)^{\star}$ \\
\hline Self employed & $76(38.2)$ & $123(61.8)$ & $3.185(1.306,7.765)^{*}$ \\
\hline Farmer & $8(30.8)$ & 18(69.2) & $2.291(1.494,3.512)^{*}$ \\
\hline Day laborer & $28(48.3)$ & $30(51.7)$ & $1.516(0.828,2.777)$ \\
\hline Others & $22(31.9)$ & $47(68.1)$ & $3.024(1.663,5.497)^{*}$ \\
\hline \multicolumn{4}{|l|}{ Monthly Income } \\
\hline$<500$ Eth.birr & $166(51.9)$ & 154(48.1) & $1.437(0.956,2.160)$ \\
\hline 500-1000 Eth.birr & $84(40.6)$ & $123(59.4)$ & $1.578(1.108,2.248)^{*}$ \\
\hline 1000-1500 Eth.birr & $32(40.0)$ & $48(60.0)$ & $1.617(0.982,2.661)$ \\
\hline$>1500$ Eth.birr & $57(42.9)$ & $76(57.1)$ & 1 \\
\hline
\end{tabular}

Table 3. Bivariate analysis between Socio Demographic and Economic variables with depression among people living with HIV on ART program in Harari region, Ethiopia,March 2013.
Those individuals who have been widowed were 3 times more likely to develop depresssion than those who have been single $(\mathrm{AOR}=3.128$, 95\% CI 1.700,5.757).Clients who were income less than 500 Eth.Birr were $92 \%$ more risk of developing depression than who had income greater than 1500 Eth.Birr. (AOR=1.924, 95\% CI 1.159,3.195).

The proportion of respondents was last time missed any of medication. Of the respondents who were missed one to two week ago were 5 times $(\mathrm{AOR}=5.274,95 \% \mathrm{CI} ; 2.583,10.768)$, more likely to develop depression than to with those missed any of medication within the past week.

The adjusted odd ratio showed that the odds number of whose had verbally stigmatized were found to be 2.7 times higher risk to depression when compared with respondents whose had no teased, insulted or sworn at (AOR=2.705, 95\%CI; 1.445, 5.063).

The adjusted odd ratio showed that the odds number times of scheduled for clinic visit in a who were attend once in a month were found to be were 22 times more likely to develop depression than who never scheduled for clinic visit in a month (AOR=22.729,95\%CI;2.450, 210.873) (Table 4).

\section{Discussion}

The overall prevalence rate of depression and verbal stigma among people living with HIV who participated in this study was $45.8 \%$ and $46.6 \%$ respectively. The total of depressed participants is in the range between $42.4 \%$ and $49.5 \%$. The study revealed that being male, widowed, less than 500 Eth.Birr, teased or sworn at, gossiped about missed any of medications and frequent of scheduled for clinic visit in a month were associated factors identified in this study.

This prevalence of depression among people living with HIV in this study is closer to the prevalence of $53 \%$. On the other hand, the rate is significantly lower than the $81 \%$ prevalence for clinically significant depression among Rwandan HIV infected women on antiretroviral therapy [11]. Similarly in a Western Kenyan provincial town, patients with HIV attending a community support group were assessed using the PHQ-9, revealed 34\% and 32\% in Malaysia. Of the respondents had depressive morbidity at any level of severity $[15,16]$.

This study showed that $27.3 \%$ of respondents had mild forms of depression and $42 \%$ reported moderate to severe depression. These rates of depression are consistent with observations in urban South Africa, which show $30 \%$ of people with HIV/AIDS indicating mild depression and [17].

Our finding shown that male living with HIV in were more likely to develop depression, the finding was differ with other the study conducted in urban south Africa, Female has been found to be associated with scoring positive to depression [18]. Also similar in other studies assessing depression in a population of HIV infected people in Uganda and Rwanda [19,20]. Research on depression in the general population have also found that gender is significantly associated with depression this means that females being more likely to have depression than males [21,22].

Like other studies conducted the prevalence in this study is greater than that found in South African and American HIV-infected populations may suggest that depression among HIV-infected patients is higher in low income countries (such as Rwanda, Uganda, Kenya and Rwanda) [11,19] than in upper middle income countries [23] and higher income countries [24]. This underscores the importance of a comparative study of prevalence of depressive disorders among HIVinfected people across countries. 


\begin{tabular}{|c|c|c|c|c|}
\hline \multirow[t]{2}{*}{ Characteristics } & \multicolumn{2}{|c|}{ Depression } & \multirow[b]{2}{*}{ COR $(95 \% \mathrm{Cl})$} & \multirow[b]{2}{*}{ AOR $(95 \% \mathrm{Cl})$} \\
\hline & YES (\%) & NO (\%) & & \\
\hline \multicolumn{5}{|l|}{ Sex } \\
\hline Male & 109(40.1) & $163(59.9)$ & $1.445(1.068,1.956)^{*}$ & $1.633(1.138,2.342)^{*}$ \\
\hline Female & $230(49.1)$ & $238(50.9)$ & 1 & 1 \\
\hline \multicolumn{5}{|l|}{ Marital status } \\
\hline Single & $39(59.1)$ & $27(40.9)$ & 1 & 1 \\
\hline Married & $167(49.0)$ & $174(51.0)$ & $1.505(0.882,2.569)$ & $1.562(0.888,2.748)$ \\
\hline Widowed & $68(35.1)$ & $126(64.9)$ & $2.676(1.510,4.745)^{\star}$ & $3.128(1.700,5.757)^{\star}$ \\
\hline Divorced/separated/cohabiting & $65(46.8)$ & $74(53.2)$ & $1.644(0.909,2.976)$ & $1.837(0.962,3.509)$ \\
\hline \multicolumn{5}{|l|}{ Monthly Income } \\
\hline$<500$ Eth.birr & 166(51.9) & 154(48.1) & $1.437(1.956,2.160)^{*}$ & $1.924(1.159,3.195)^{\star}$ \\
\hline 500-1000 Eth.birr & $84(40.6)$ & $123(59.4)$ & $1.578(0.108,2.248)$ & $2.946(0.538,5.645)$ \\
\hline 1000-1500 Eth.birr & $32(40.0)$ & $48(60.0)$ & $1.617(0.982,2.661)$ & $1.366(0.715,2.609)$ \\
\hline >1500 Eth.birr & $57(42.9)$ & $76(57.1)$ & 1 & 1 \\
\hline \multicolumn{5}{|l|}{ Verbal stigma } \\
\hline Yes & 95(23.4) & $324(77.3)$ & 1 & 1 \\
\hline No & $244(22.7)$ & $77(24.0)$ & $11.143(7.873,15.770)^{*}$ & $2.705(1.445,5.063)^{*}$ \\
\hline \multicolumn{5}{|c|}{$\begin{array}{l}\text { When was the last time you missed any of your } \\
\text { medications }\end{array}$} \\
\hline Within the past week & $54(54.5)$ & $45(45.5)$ & 1 & 1 \\
\hline One to two weeks ago & $16(21.6)$ & $58(78.4)$ & $4.350(2.203,8.589)^{\star}$ & $4.135(1.871,9.139)^{*}$ \\
\hline Two to four weeks ago & $20(20.8)$ & $76(79.2)$ & $4.560(2.424,8.577)^{\star}$ & $5.274(2.583,10.768)^{*}$ \\
\hline One to three months ago & $9(31.0)$ & $20(69.0)$ & $2.667(1.105,6.433)^{*}$ & $3.715(1.390,9.933)^{\star}$ \\
\hline More than 3 months ago & $28(45.9)$ & $33(54.1)$ & $1.414(0.745,2.683)$ & $1.537(0.781,3.027)$ \\
\hline $\begin{array}{l}\text { Never skipped medications } \\
\text { Within the past week }\end{array}$ & 169(63.1) & $99(36.9)$ & $0.703(0.441,1.121)$ & $0.670(0.383,1.170)$ \\
\hline \multicolumn{5}{|c|}{$\begin{array}{l}\text { How frequent are you scheduled for clinic visit } \\
\text { in a month }\end{array}$} \\
\hline Never & $15(93.8)$ & $1(6.2)$ & 1 & 1 \\
\hline Once in a month & 153(44.9) & $188(55.1)$ & $18.431(2.408,141.106)^{*}$ & $19.033(2.095,172.878)^{*}$ \\
\hline Twice a month & $36(55.4)$ & $29(44.6)$ & $12.083(1.506,96.961)^{*}$ & $13.784(1.430,132.871)^{*}$ \\
\hline$>=3$ times in a month & $135(42.5)$ & $183(57.5)$ & $20.625(2.690,158.145)^{*}$ & $22.729(2.450,210.873)^{*}$ \\
\hline
\end{tabular}

*significant association $(p<0.05)$

Table 4. Multivariable logistic regression about depression among people living with HIV on ART program Harari Region Eastern Ethiopia, 2013.

In this study, marital status of the respondents was an important factor associated with depressive morbidity. Widowed PLWHA were more likely to have depression than patients who are single, Similarly, finding was found to be in consistence with study done in Rwanda those who were widowed and who were divorced, were more likely to be depressed(59.3\% and $42.9 \%$ respectively) than those who were single was found to be in differ with study done in the South India married PLWHA were 6 times more likely to have depression as compared to single PLHA found that married PLWHA were more likely to have depression and the potential reasons could be the responsibility to take care of the children and family and fear of disclosing the status to the family members due to concerns of losing social and economic support [25].

This study also highlighted several forms of internalized stigma reported by PLWHA. The most Prevalent losses were reported within the forms of verbal stigma. Of the two items assessing teased, insulted or sworn at, who $89.0 \%$ perceived they had gossiped about various qualitative studies support presence of patterns that reflect negative attitudes towards PLWHA in the community and from health care providers [26,27] that would support these high reported levels of internalized stigmatizing.

The study sites at the clinic that was required that mild depressive symptoms $18.8 \%$ missed the last time medication did $39.1 \%$ of those with moderate to severe depression $[20,28]$. The other variable that is statistically significant in multiple logistic regression analysis patients who were last time missed their time medication had risk of depression using categories such as has one to two weeks ago, two to four weeks ago and one to three month ago (4,5 and 3 times respectively) were more likely to be depressed this study revealed a that $48.5 \%$ missed their last time medication. Similarly, in Nigeria $52.2 \%$ on antiretroviral medication skipped their doses antiretroviral medication skipped their doses due tiredness of taking medication.

Respondents who scheduled to visit clinic within a month was assessed using categories such as has never been to the clinic, has been to the clinic once, has been to the twice clinic 3 times or more. 3 times or more found to be 22 times more likely to be depressed than never scheduled to visit ART clinic this finding was found to be in contrast with the study conducted in Tanzania and Rwanda [28].

\section{Limitation of the Study}

The interpretation of the findings of this study should consider the following potential limitations; Firstly, the cross sectional nature of this study may limit the causal and effect interpretation of the factors observed Therefore, the data collected might not be as accurate there might be recall bias from participants. Secondly, since the study was institutional based it might not generalized to the total population of people living with HIV in the region. 


\section{Conclusion}

From the findings of this study, it emerged the prevalence of depression was $48.5 \%$ and verbal stigma $56.6 \%$ among people living with HIV who participated in the study. The majority of participants who scored positive to depression had mild to moderate depression and very few had severe depression. Socio-demographic factors and HIV medical related factors that were studied, being a male and lack of social support were statistically associated with depression. On the other hand, in this study depressive morbidity was more consistently associated with poor uptake of medical recommendations including missed their last time medication and patients to attend an individual counseling session. Other predisposing factor for development of depression was stigma through impacts on teased, insulted or sworn at and gossiped about. Future research to better understand the mechanisms of associations between stigma and depression in PLWHA are necessary; as well as studies to inform development of stigma and depression reduction interventions.

\section{Acknowledgement}

We are highly indebted to Harari Regional Educational Bureau, for sponsoring this research. We would like to extend our thanks to all Health facilities administrators for permitting us to conduct the study. We would also like to extend our appreciation to the study participants, supervisors and data collectors.

\section{References}

1. Prince M, Patel V, Saxena S, Maj M, Maselko J, et al. (2007) No health without mental health. Lancet 370: 859-877.

2. Federal HIVIAIDS prevention and control office (2007) Trends in HIVIAIDS prevalce.

3. WHO (2010) Mental health and development, targeting people with mental health condition as a vulnerable group.

4. Rabkin JG (2008) HIV and depression: 2008 review and update. Curr HIV/AIDS Rep 5: 163-171.

5. Berhe H, Bayray A (2013) Prevalence of Depression and associated factors among people living with HIVIAIDS in Tigray, North Ethiopia: a Cross Sectional Hospital based study. Int J Pharm Sci Res 4: 765-775.

6. Berger-Greenstein JA, Cuevas CA, Brady SM, Trezza G, Richardson MA, et al. (2007) Major depression in patients with HIVIAIDS and substance abuse. AIDS Patient Care STDS 21: 942-955.

7. Ciesla JA, Roberts JE (2001) Meta-analysis of the relationship between HIV infection and risk for depressive disorders. Am J Psychiatry 158: 725-730.

8. WHO (2008) HIVIAIDS and mental health. Report by the Secretariat, Executive Board, EB124/6, 124th Session.

9. Gordillo V, del Amo J, Soriano V, González-Lahoz J (1999) Sociodemographic and psychological variables influencing adherence to antiretroviral therapy. AIDS 13: 1763-1769.

10. Theodros S, Abraham H, Belayneh G (2008) Effect Of Acess To Antiretrovira Therapy On Stigma, Jimma University Hospital, Southwest Ethiopia. Ethiop J Health Sci 18: 25-32.

11. Amsalu B, Gashaw A, Minale T, Tigabu B, Telake A (2014) Prevalence of Anxiety and Associated Factors among People Living with HIVIAIDS at Debretabor General Hospital Anti Retro Viral Clinic Debretabor, Amhara, Ethiopia, 2014. American Journal of Psychiatry and Neuroscience 2: 109-114

12. Tesfaye SH, Bune GT (2014) Generalized psychological distress among HIVinfected patients enrolled in antiretroviral treatment in Dilla University Hospital, Gedeo zone, Ethiopia. Glob Health Action 7: 23882.
13. Reus VI (2005) Harrison's principles of internal medicine. Edited by Kasper DL (16th Edn.), McGraw-Hill, New York.

14. Kroenke K, Spitzer RL (2002) The PHQ-9: A new depression and diagnostic severity measure. Psychiatric Annals 32: 509-521.

15. Cohen J (1992) A power primer. Psychol Bull 112: 155-159.

16. Monahan PO, Shacham E, Reece M, Kroenke K, Ong'or WO, et al. (2009) Validity/reliability of $\mathrm{PHQ}-9$ and $\mathrm{PHQ}-2$ depression scales among adults living with HIVIAIDS in western Kenya. J Gen Intern Med 24: 189-197.

17. Simbayi LC1, Kalichman S, Strebel A, Cloete A, Henda N, et al. (2007) Internalized stigma, discrimination, and depression among men and women living with HIVIAIDS in Cape Town, South Africa. Soc Sci Med 64: 1823-1831.

18. Sayles JN, Wong MD, Kinsler JJ, Martins D, Cunningham WE (2009) The association of stigma with self-reported access to medical care and antiretroviral therapy adherence in persons living with HIVIAIDS. J Gen Intern Med 24: 1101-1108.

19. Israelski DM, Prentiss DE, Lubega S, Balmas G, Garcia P, et al. (2007) Psychiatric co-morbidity in vulnerable populations receiving primary care for HIVIAIDS. AIDS Care 19: 220-225.

20. Kaharuza FM, Bunnell R, Moss S, Purcell DW, Bikaako-Kajura W, et al. (2006) Depression and CD4 cell count among persons with HIV infection in Uganda. AIDS Behav 10: S105-111.

21. Riolo SA, Nguyen TA, Greden JF, King CA (2005) Prevalence of depression by race/ethnicity: findings from the National Health and Nutrition Examination Survey III. Am J Public Health 95: 998-1000.

22. Mason KI, Evans DL (2010) Neuropsychiatric Manifestations of HIV-1 Infection and AIDS. Neuropsychopharmacology. The Fifth Generation of Progress, $1281-1300$.

23. Myer L, Smit J, Roux LL, Parker S, Stein DJ, et al. (2008) Common mental disorders among HIV-infected individuals in South Africa: Prevalence, predictors, and validation of brief psychiatric rating scales. AIDS Patient Care and STDs 22: 147-158.

24. Morrison MF, Petitto JM, Ten Have T, Gettes DR, Chiappini MS, et al. (2002) Depressive and anxiety disorders in women with HIV infection. Am J Psychiatry 159: 789-796.

25. Charles B, Jeyaseelan L, Pandian AK, Sam AE, Thenmozhi M, et al. (2012) Association between stigma, depression and quality of life of people living with HIVIAIDS (PLHA) in South India - a community based cross sectional study. BMC Public Health 12: 463.

26. Mahendra VS, Gilborn L, Bharat S, Mudoi R, Gupta I, et al. (2007) Understanding and measuring AIDS-related stigma in health care settings: a developing country perspective. SAHARA J 4: 616-625.

27. Nyablade L, Mac Quarrie, Fausta Phillip, Gideon Kwesigabo, Jessie Mbwambo et al. (2005) Working report: Measuring HIV stigma: results of a field test in Tanzania. United States Agency for International Development, CNLS.

28. Li L, Lee SJ, Thammawijaya P, Jiraphongsa C, Rotheram-Borus MJ (2009) Stigma, social support, and depression among people living with HIV in Thailand. AIDS Care 21: 1007-1013. 